\title{
Real life second-line nivolumab in advanced non-small cell lung cancer: A French observational multicenter study of 259 patients (ABCT-IMMUNOBZH)
}

Margaux Geier ${ }^{*}$, Renaud Descourt ${ }^{1}$, Romain Corre $^{2}$, Guillaume Léveiller $^{3}$, Régine Lamy ${ }^{4}$, Éric Goarant $^{5}$, Jean-Louis Bizec ${ }^{6}$, Cyril Bernier $^{7}$, Gilles Quéré $^{8}$, Elisabeth Gaye ${ }^{1}$, François Montestruc ${ }^{9}$, Francis Couturaud ${ }^{1,10}$ and Gilles Robinet $^{1}$

${ }^{1}$ Department of Oncology, CHRU Morvan, University Hospital of Brest, Brest, France

${ }^{2}$ Department of Pulmonary Diseases, CHU Pont Chaillou, University Hospital of Rennes, Rennes, France

${ }^{3}$ Department of Pulmonary Diseases, CH Yves le Foll, Hospital of Saint-Brieuc, Saint-Brieuc, France

${ }^{4}$ Department of Oncology, CH Bretagne Sud, Hospital of Lorient, Lorient, France

${ }^{5}$ Department of Pulmonary Diseases, Hospital of Saint-Malo, Saint-Malo, France

${ }^{6}$ Department of Pulmonary Diseases, CH Bretagne-Atlantique, Hospital of Vannes, Vannes, France

${ }^{7}$ Department of Pulmonary Diseases, CH Rene Pleven, Hospital of Dinan, Dinan, France

${ }^{8}$ Department of Pulmonary Diseases, Hospital of Morlaix, Morlaix, France

${ }^{9}$ XXYSTAT, Malakoff, France

${ }^{10} \mathrm{EA} 3878$ (GETBO) University of Brest, Brest, France

\author{
Research highlights \\ » Nivolumab provides an objective response rate of $22.4 \%$ in a real-life setting. \\ »Survival data in a real-life setting are similar than published clinical trials. \\ » Nivolumab confirms a satisfactory safety profile in unselected patients. \\ » Occurrence of immune-related adverse events was correlated with efficacy.
}

\begin{abstract}
Introduction: Data regarding nivolumab as second line treatment in advanced non-small cell lung cancer (NSCLC) are based on selected populations and might not reflect daily practice. We aimed at assessing efficacy and safety of nivolumab in a real-life setting and determining a subtype of NSCLC patients that are more likely to benefit from immunotherapy.

Methods: Between 01/09/2015 and 30/09/2016, all consecutive advanced NSCLC patients treated with nivolumab after failure of at least one line of chemotherapy were included. Nivolumab was administered at a dose of $3 \mathrm{mg} / \mathrm{kg} \mathrm{q} 2 \mathrm{w}$ until progression or unacceptable toxicity. Primary endpoint was objective response rate (ORR), according to RECIST 1.1. Progression-free survival (PFS), overall survival (OS) and predictive factors were secondary objectives.

Results: 259 patients treated with nivolumab were enrolled from 9 centers. The main characteristics of patients at baseline were: median age of 62 y [29-85]; 72.2\% of males; $73 \%$ with PS $\leq 1$ and $85.8 \%$ of smokers. There were $85.3 \%$ with a stage IV disease, $63.7 \%$ with adenocarcinoma. $61.4 \%$ of pts received nivolumab in second line. ORR was 22.4\% [17.7\%; 27.9\%]. Median PFS and OS were 2.3 [1.9-3.3] and 11.0 [8.9-14] months respectively. Multivariate analysis confirmed that squamous histology was correlated with better response (HR=1.98, 95\% CI [1.08-3.61], $p=0.03$ ) and occurrence of Immune-Related Adverse Events (IRAEs) with both better response and $\mathrm{OS}(\mathrm{HR}=2.41,[1.21-4.80], p=0.01$ and $\mathrm{HR}=0.42,95 \% \mathrm{CI}[0.26-0.70], p<0.01$ respectively).
\end{abstract}

Conclusion: Our study confirms the efficacy of nivolumab in real-life setting with a satisfactory safety profile. Squamous histology and occurrence of IRAEs emerge as predictive factors.

\section{Introduction}

Immunotherapy has recently evolved into a new standard of care for second-line treatment in patients with advanced non-small cell lung cancer (NSCLC) [1]. Nivolumab is the first PD-1 antibodymediated inhibitor approved in second line treatment of squamous cell (SCC) and non-squamous cell carcinoma [2], as demonstrated by two phase III randomized trials, which compared nivolumab to standard
${ }^{*}$ Correspondence to: Geier Margaux, MD, Institut de Cancérologie, Hôpital Morvan, 2 avenue Foch, 29200 BREST, France, Tel: 33298223333; Fax: 33298223498; E-mail: margaux.geier@gmail.com

Key words: real-life, nivolumab, efficacy, NSCLC

Received: August 24, 2018; Accepted: September 17, 2018; Published: September 20, 2018 
chemotherapy by docetaxel $[3,4]$. Both studies have shown a gain of three months on overall survival with nivolumab. Response rates (ORR) were higher in patients treated by immunotherapy $(20 \%[3]$ and $19 \%$ [4]) than chemotherapy $(8,8 \%$ [3] and $12 \%$ [4]). This antitumor response was maintained independently of PD-L1 expression. Two other phase III studies assessing pembrolizumab (anti-PD-1), for patients with an expression of PD-L1 $\geq 1 \%$, and atezolizumab (anti PDL1) also demonstrated a superiority of immunotherapy on docetaxel $[5,6]$. However, response to nivolumab remains heterogeneous and difficult to predict. While a subgroup of patients has a prolonged response under nivolumab, other has deleterious outcomes with immunotherapy comparing standard chemotherapy. These seemingly contradictory results suggest the existence of two subpopulations of patients with underlying predictive features yet to be identified [4].

Current data regarding the efficacy of nivolumab are derived from prospective and patient-selected studies and/or included in compassionate programs that do not reflect daily clinical practice. The main objective of this study was to evaluate the therapeutic effectiveness of nivolumab in the real-life setting. The secondary purpose was to determine a subtype of NSCLC patients that are more likely to benefit from immunotherapy, which is still one of the current challenges in thoracic oncology.

\section{Methods}

\section{Study population and procedures}

We conducted a multicenter, non-interventional, retrospective cohort study in nine centers throughout the Brittany region, France.

Patients with advanced NSCLC (stage IIIB-IV) treated with nivolumab were eligible after failure of at least one line of chemotherapy. Because marketing authorisation of nivolumab being independent of PD-L1 expression, this data was not filled. Other essential inclusion criteria were: age $\geq 18$ years, initiation of nivolumab between 01/09/2015 and 30/09/2016. Patients were excluded if they started nivolumab after October 2016, participated in an immunotherapy trial or expressed their refusal to participate. Nivolumab was administered intravenously at a dose of $3 \mathrm{mg} / \mathrm{kg}$ of body weight every 15 days until progression according to RECIST criteria 1.1 or unacceptable toxicity.

During the investigation period, patients were selected from each center's database according to the inclusion criteria. Access to the databases was provided by the first author in association with the referents of each center participating in the study.

\section{Study endpoints}

The primary endpoint was to assess the efficacy of nivolumab in real life in terms of objective response rate (ORR), according to RECIST 1.1 criteria [7] evaluated by the investigators of each center and analyzed by intention-to-treat. Secondary objectives were to evaluate disease control rate (DCR), progression-free survival (PFS), as the time from nivolumab initiation to first sign of progression, and overall survival (OS), as the time from nivolumab initiation to death from any cause. Other secondary objectives were to analyze safety profile of nivolumab according to CTCAE v 4.0 criteria [8] especially occurrence of Immune-Related Adverse Events (IRAEs) defined as autoimmune toxicity attributed to nivolumab and to evaluate the response to chemotherapy post-immunotherapy. Finally, we aimed to correlate clinico-pathological features to response and survival in order to identify potential predictive markers. Different parameters were collected: clinical (age, sex, ECOG PS, smoking history and weight loss since cancer diagnosis), biological (Lymphocytes (Lc), Neutrophils (PNN), Eosinophils counts (Ec), LDH level and albumin level at the time of nivolumab initiation), pathological (histology and KRAS mutation status) and therapeutic (prior radiotherapy, type of response to previous treatment(s)).

\section{Study oversight}

This non-interventional study was approved by a regional ethics committee and France's national data protection authority (CNIL), according to French law.

\section{Statistical analysis}

Based on a study population of 250 patients, a two-sided $95 \%$ confidence interval (CI) for a single proportion using the large sample normal approximation will extend $5 \%$ from the observed proportion for an expected proportion of ORR of $20 \%$. Statistical analysis was conducted using SAS $^{\circledast}$ software (SAS Institute, North Carolina, USA) V9.4 on Windows ${ }^{\mathrm{m}}$. Continuous variables were described by the number of valid cases and missing data, mean, standard deviation, median, Q1, Q3, minimum, and maximum. Categorical variables were described as the total number and percentage per category. For primary analysis, Wald 95\% two-sided confidence intervals of the ORR were calculated. For ORR, missing data was considered as non-responder. A Cox/logistic model including all the factors identified was performed for OS/PFS/ORR.

First, univariate analyses using the logrank/ $/ \mathrm{Chi}^{2}$ test were done to identify variables to enter in the multivariate Cox/logistic model. Variables with a significant $p$ value on univariate analysis and variables that are deemed clinically important were entered in a multivariate Cox/logistic model with backward selection. The usual rate of 1 variable for 10 events will be followed in the Cox/logistic model. Hazard ratios (HR)/Odd ratios and associated 95\% CI were provided. Statistical significance was set at $p$ less than 0.05 .

\section{Results}

\section{Patient characteristics}

Between September $1^{\text {st }}, 2015$ and September $30^{\text {th }}, 2016,337$ patients were selected for data collection and analysis. Final analysis was conducted on a total of 259 patients. Patient selection is shown in Figure 1. The baseline clinicopathological characteristics of patients are summarized in Table 1 . In the studied population, $72.2 \%$ of the patients were men, with a median age of 62 years [29-85]. $73 \%$ had PS $\leq 1$ and $85.8 \%$ a smoking history. $85.3 \%$ of the patients had stage IV disease, $20.5 \%$ with brain metastasis at baseline. The main pathological type was adenocarcinoma (63.7\%). Status towards KRAS mutation was assessed for 180 patients and found in $30.6 \%$ of cases (Supplementary Figure 1).

Patient characteristics at the time of nivolumab initiation are shown in Table 2. $61.4 \%$ of patients received nivolumab in second line treatment. In most cases, a platinum based-doublet with pemetrexed was administered for first line systemic therapy. About $60 \%$ of patients had responded to one or more previous treatment(s), mostly chemotherapy; $45.2 \%$ were responders to the treatment line prior to nivolumab. $50.6 \%$ of patients had received radiation therapy previously - either curative or palliative. The biological characteristics at initiation of nivolumab are shown in the appendix (Supplementary Table 1). Most patients had a satisfactory nutritional status (albumin level $\geq 30 \mathrm{~g} / \mathrm{l}$ ) and moderate systemic inflammation, with a blood count of PNN $<7$ $\mathrm{G} / \mathrm{l}$ and $\mathrm{Lc}>1 \mathrm{G} / \mathrm{l}$. 


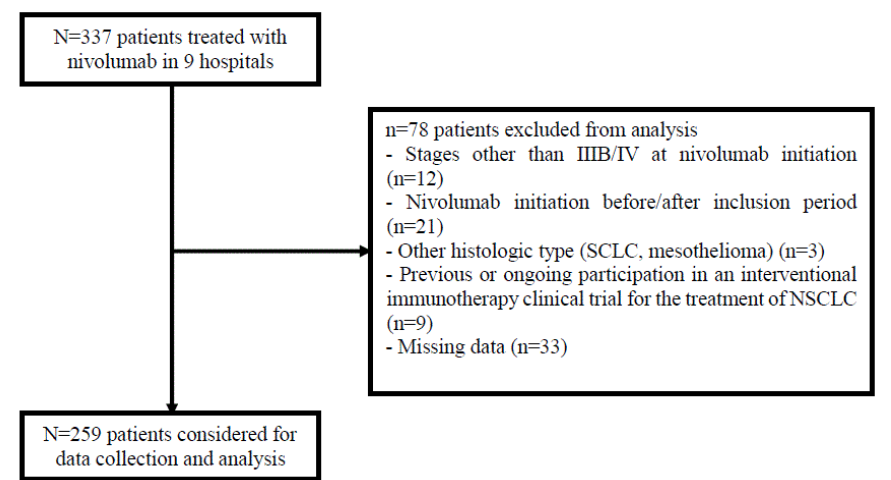

Figure 1. Study flow chart

Table 1. Baseline clinicopathological characteristics of patients

\begin{tabular}{|c|c|}
\hline & Total $(\mathrm{N}=259)$ \\
\hline \multicolumn{2}{|l|}{ Age (years) } \\
\hline Mean (SD) & $61.9(9.6)$ \\
\hline Median [Range] & $62.0[29.0-85.0]$ \\
\hline$<70$ & $205(79.2 \%)$ \\
\hline$\geq 70$ & $54(20.8 \%)$ \\
\hline \multicolumn{2}{|l|}{ Sex } \\
\hline $\mathrm{F}$ & $72(27.8 \%)$ \\
\hline $\mathrm{M}$ & $187(72.2 \%)$ \\
\hline \multicolumn{2}{|l|}{ Smoking status } \\
\hline Never-smoker & $23(8.9 \%)$ \\
\hline Current-smoker & $111(42.9 \%)$ \\
\hline Former-smoker & $111(42.9 \%)$ \\
\hline MD & $14(5.4 \%)$ \\
\hline \multicolumn{2}{|l|}{ Pack-years number } \\
\hline$<25$ & $36(13.9 \%)$ \\
\hline $25-50$ & $126(48.6 \%)$ \\
\hline$>50$ & $34(13.1 \%)$ \\
\hline MD & $63(24.3 \%)$ \\
\hline \multicolumn{2}{|l|}{ ECOG PS } \\
\hline PS 0-1 & $189(73.0 \%)$ \\
\hline PS $>1$ & $15(5.8 \%)$ \\
\hline MD & $55(21.2 \%)$ \\
\hline \multicolumn{2}{|l|}{ Stage at diagnosis } \\
\hline IIIB & $38(14.7 \%)$ \\
\hline IV & $221(85.3 \%)$ \\
\hline Single site & $109(42.1 \%)$ \\
\hline Multisite & $112(43.2 \%)$ \\
\hline \multicolumn{2}{|l|}{ Histology } \\
\hline Adenocarcinoma & $165(63.7 \%)$ \\
\hline Squamous cell carcinoma & $70(27.0 \%)$ \\
\hline Undifferentiated non-small cell carcinoma & $18(6.9 \%)$ \\
\hline Other & $6(2.4 \%)$ \\
\hline Brain metastasis at diagnosis & $53(20.5 \%)$ \\
\hline
\end{tabular}

MD: Missing data

ECOG PS: Eastern cooperative oncology group performance status

\section{Efficacy of nivolumab}

\section{Response to nivolumab}

With a median follow-up of 17.7 months [16.7-19.0], the ORR was $22.4 \%$ [17.7\%; $27.9 \%$ ], including one patient $(0.4 \%)$ with complete response and $57(22.0 \%)$ with partial response. $46.0 \%$ of the patients progressed at first evaluation. The DCR was $42.5 \%$ [36.6\%; $48.6 \%$ ]. No evaluation could be carried out on 30 patients (11.6\%) because of poor general condition or early deaths (Table 3 ). The median duration of response was not reached $[8.1 ; \mathrm{NR}]$. Among the 58 responders, only 12 progressions were observed during the follow-up and 6-months PFS rate was of $76.7 \%$ [59.8; 87.2].

\section{Survival}

The median PFS was 2.3 months [1.9-3.3] (Figure 2). The 6-, 12and 18- month PFS rates were $32.2 \%$ [26.5-38.0], 21.5\% [16.2-27.2] and $13.5 \%$ [7.7-20.9] respectively. The median OS was 11.0 months [8.9-14]. The 6, 12- and 18- month survival rates were $67.8 \%$ [61.7-73.2], $47.9 \%$ [41.5-53.9] and 36.6\% [30.2-43.0] respectively.

\section{Safety and tolerability}

One hundred patients (38.6\%) presented one or more toxicity(s) during immunotherapy. Main toxicities are summarized in the Supplementary Table 2. The most frequent were dysthyroidism (13.5\%), mostly grade 1-2, followed by cutaneous and digestive toxicities (10\% and $7.7 \%$ respectively). Myalgia was observed in 18 patients (6.9\%). IRAEs have been frequently described, in at least $20 \%$ of cases. Rare cases of autoimmune toxicities have been reported: type 1 diabetes, Behçet's disease, rheumatoid arthritis, adrenal insufficiency, peripheral gonadotropin deficiency, pancytopenia, leading to treatment discontinuation. 37 patients (14.3\%) experienced grade 3-4 toxicities attributed to nivolumab. None of them were fatal.

\section{Predictive factors of efficacy}

An analysis of different clinico-pathological features influencing efficacy to nivolumab in terms of response and survival has been performed. In the univariate analysis, squamous histology was statistically associated with a better response $(\mathrm{HR}=2.09$, [1.16-3.79], $p=0.01)$ as Lc $\geq 1 \mathrm{G} / \mathrm{L}$ at initiation of nivolumab $(\mathrm{HR}=0.16$, [0.040.72 ] $p=0.02)$, prior radiotherapy $>6$ months $(\mathrm{HR}=14.08,[5.36-37.01]$, $p<0.01)$ ) and occurrence of IRAEs (HR=2.57, [1.30-5.05], $p<0.01)$

Table 2. Population characteristics at the time of nivolumab initiation

\begin{tabular}{|c|c|}
\hline & Total $(\mathrm{N}=259)$ \\
\hline \multicolumn{2}{|l|}{ Number of previous line(s) } \\
\hline Median & $1(1-6)$ \\
\hline 1 & $159(61.4 \%)$ \\
\hline 2 & $69(26.6 \%)$ \\
\hline$\geq 3$ & $31(12 \%)$ \\
\hline \multicolumn{2}{|l|}{ ECOG PS } \\
\hline$\leq 1$ & $146(77.2 \%)$ \\
\hline$>1$ & $43(22.8 \%)$ \\
\hline MD & 70 \\
\hline \multicolumn{2}{|l|}{ Weight loss since diagnosis } \\
\hline$\leq 10 \%$ & $153(78.9 \%)$ \\
\hline$>10 \%$ & $41(21.1 \%)$ \\
\hline MD & 65 \\
\hline \multicolumn{2}{|l|}{ Best response to previous treatment(s) } \\
\hline Complete response & $6(2.3 \%)$ \\
\hline Partial response & $153(59.1 \%)$ \\
\hline Stable disease & $51(19.7 \%)$ \\
\hline Progressive disease & $44(17.0 \%)$ \\
\hline Not evaluated & $5(1.9 \%)$ \\
\hline \multicolumn{2}{|l|}{ Prior radiotherapy } \\
\hline Yes & $131(50.6 \%)$ \\
\hline No & $128(49.4 \%)$ \\
\hline Prior radiotherapy $>6$ months $(\mathrm{N}=131)$ & $54(20.8 \%)$ \\
\hline Prior radiotherapy $<6$ months $(\mathrm{N}=131)$ & $77(29.7 \%)$ \\
\hline
\end{tabular}

ECOG PS: Eastern cooperative oncology group performance status MD: Missing data 


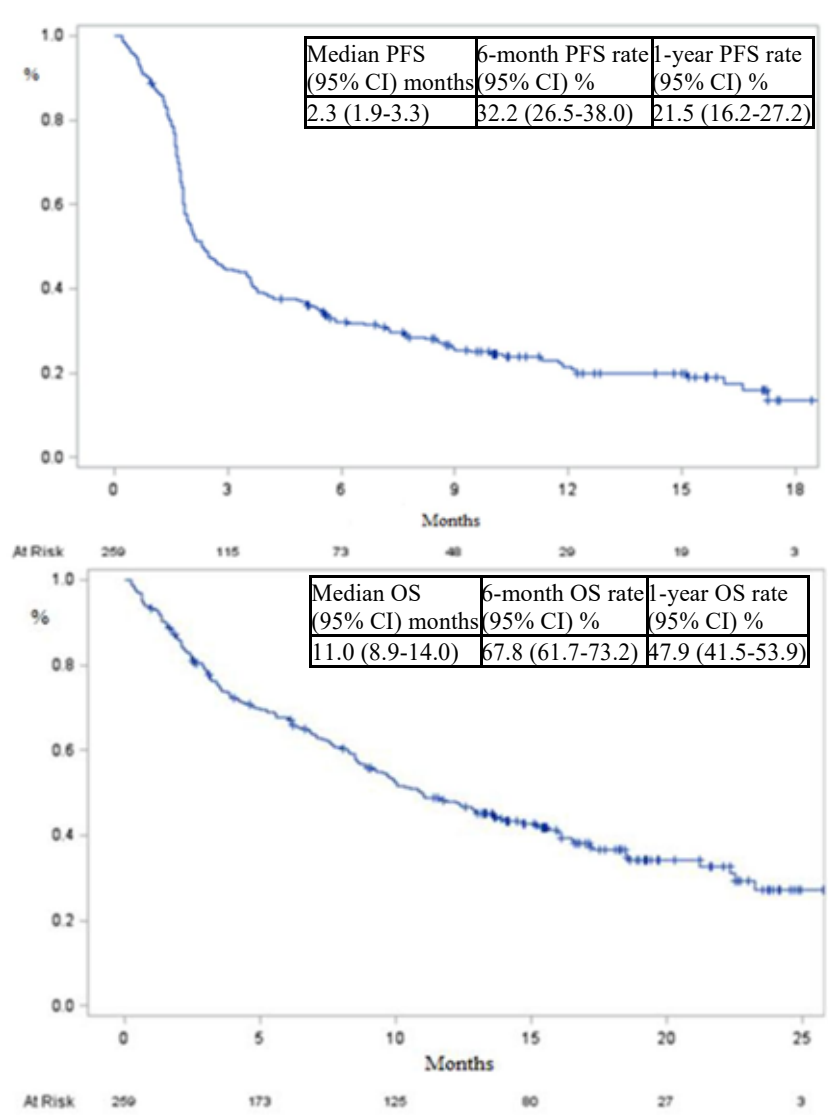

Figure 2. Survival data

Table 3. Detail of nivolumab response (Intention-to-treat analysis)

\begin{tabular}{|l|c|}
\hline & Total (N=259) \\
\hline Objective Response Rate (ORR) & $58(22.4 \%)$ \\
\hline Complete Response (CR) & $1(0.4 \%)$ \\
\hline Partial Response (PR) & $57(22.0 \%)$ \\
\hline Stable Disease (SD) & $52(20.1 \%)$ \\
\hline Disease Control Rate (DCR) & $110(42.5 \%)$ \\
\hline Progressive Disease (PR) & $119(46.0 \%)$ \\
\hline Not evaluable (NE) & $30(11.6 \%)$ \\
\hline Median follow-up (months) & $17.7[16.7 ; 19.0]$ \\
\hline Median Duration of Response (months) & $\mathrm{NR}[8.1 ; \mathrm{NR}]$ \\
\hline Median time to response (days) & $58[43-194]$ \\
\hline Median Duration of Disease Control (months) & $10[7.7 ; \mathrm{NR}]$ \\
\hline Median Time to Progression (months) & $3.3[2.3 ; 4.2]$ \\
\hline
\end{tabular}

NR: Not reached

(Table 4). PFS was also improved with squamous histology $(\mathrm{HR}=0.70$, $[0.52-0.95], p=0.02)$, prior radiotherapy $>6$ months $(\mathrm{HR}=0.2,[0.12-$ $0.34], p<0.01)$ and occurrence of IRAEs (0.46, [0.30-0.68], $p<0.01)$. Concerning OS improvement, response or stability to systemic treatment(s) prior to nivolumab and IRAEs were predictive factors of efficacy (HR=0.56, [0.38-0.82], $p<0.01$ and $\mathrm{HR}=0.42,[0.26-0.68]$, $p<0.01$ respectively). Weight loss $>10 \%$ since diagnosis, $\mathrm{Lc}<1 \mathrm{G} / 1$, PNN $>7 \mathrm{G} / 1$, albumin level $<30 \mathrm{~g} / \mathrm{l}$, radiotherapy within the 6 months preceding nivolumab initiation were statistically associated with an increased risk of death. Presence of KRAS mutation, age $\geq 70$ years at diagnosis, and PS $>1$ at nivolumab initiation did not appear to be predictive of mortality. In addition, no correlation was established between smoking history or histological subtype and OS.
Multivariate analysis confirmed that predominantly squamous histology and IRAEs were correlated with better response (HR $=1.98$, [1.08-3.61], $p=0.03$ and $\mathrm{HR}=2.41,[1.21-4.80], p=0.01$ respectively). Response rate was $37.5 \%$ (18/48) for patients with IRAEs whereas it was $19.0 \%(40 / 211)$ for patients without IRAEs. PFS improvement was statistically associated with squamous histology (4.1 months [2.17.0] versus 2.1 months for adenocarcinoma [1.8-2.7], $p=0.02)$ and occurrence of IRAEs (8.8 months [3.9-17.3] versus 2 months [1.8-2.4], $p<0.01)$. Multivariate analysis revealed response or stability to systemic treatment(s) prior to nivolumab and the absence of prior radiotherapy, as markers statistically associated with increased OS (HR $=0.56$ [0.39-0.83], $p<0.01$ and $\mathrm{HR}=1.67$ [1.21-2.30], $p<0.01$ respectively) (Supplementary Table 3 ). The occurrence of IRAEs was also correlated to better OS $(\mathrm{HR}=0.42[0.26-0.70], p<0.01)$.

\section{Response to post-nivolumab systemic treatments}

At the time of data analysis, 165 patients (63.7\%) experienced progressive disease with nivolumab. Among them, 106 patients (64.2\%) received post-nivolumab systemic treatment while therapeutic abstention was decided for 59 patients (35.8\%). The drugs used in the first and second line post-nivolumab and the type of response are detailed in the appendix (Supplementary Table 4). In the first postprogression line, taxane-based monochemotherapy was most frequent (41 patients) with an ORR of $17 \%$; secondly, gemcitabine with an ORR of $11.5 \%$. The ORR in $1^{\text {st }}$ line post-nivolumab progression was $14.2 \%$. Only 27 patients received a second line post nivolumab, mainly chemotherapy, with a response rate of $18.5 \%$. The post-progression OS was 5.6 months [4.6-7.0].

\section{Discussion}

The results of this study confirm the efficacy of nivolumab, in a real-life setting, with an ORR of $22.4 \%$ and a DCR of $42.5 \%$ in second or subsequent line of treatment of advanced NSCLC. We report a median PFS of 2.3 months and a median OS of 11 months after initiation of nivolumab, with a satisfactory safety profile Furthermore, predominantly squamous-cell carcinoma was correlated with better response and occurrence of IRAEs with both better response and OS.

Randomized clinical trials are designed to evaluate efficacy of new treatments in selected patients who do not represent the entire population of lung cancer. Therefore, it seemed essential to compare the results of phase III trials with real life, in all-comer patients treated in daily practice [9]. Interestingly, we report an ORR of $22.4 \%$ with nivolumab, similar than previous results published in CheckMate-017 and 057 studies (20\% and 19\% respectively) evaluating nivolumab in second-line treatment $[3,4]$. The DCR and PD rate are similar to those described in studies. Although several characteristics of patients were similar, $45.2 \%$ were responders to the treatment line prior to nivolumab in our study versus $36 \%$ [3] and $25 \%$ [4] in previous studies, which could explain these results. We describe median PFS of 2.3 months, similar than published results and perhaps explained by adenocarcinoma as histological predominant subtype. Median OS of 11 months is better than the one reported in Checkmate-017 but slightly shorter than other estimations [4-6]. With nearly $40 \%$ of the cohort presenting toxicity and less than $15 \%$ with grades 3-4, nivolumab confirms a good safety profile. Patients did not appear to have any increased risk in routine.

Search for predictive biomarkers of response to PD-1/PD-L1 inhibition likely to improve survival is currently a major issue in immuno-oncology [10-12]. In this study, we evaluated epidemiological, clinical and biological markers. The role of the histological subtype 
Geier M (2018) Real life second-line nivolumab in advanced non-small cell lung cancer: A French observational multicenter study of 259 patients (ABCTIMMUNOBZH)

Table 4. Analysis of factors influencing response to nivolumab

\begin{tabular}{|c|c|c|c|c|c|c|}
\hline & \multirow[b]{2}{*}{ Tested } & \multirow[b]{2}{*}{ Reference } & \multicolumn{2}{|l|}{ Univariate analysis } & \multicolumn{2}{|c|}{ Multivariate analysis } \\
\hline & & & $\operatorname{HR}(95 \% \mathrm{CI})$ & $p$ value & HR $(95 \% \mathrm{CI})$ & $p$ value \\
\hline Age & $<70$ years & $\geq 70$ years & $1.35[0.63-2.87]$ & 0.44 & - & - \\
\hline Sex & Female & Male & $0.61[0.30-1.24]$ & 0.17 & - & - \\
\hline PS & $>1$ & $\leq 1$ & $0.22[0.03-1.69]$ & 0.14 & - & - \\
\hline Smoking status & Current smoker & Never/former smoker & $1.69[0.93-3.08]$ & 0.09 & - & - \\
\hline Histology & Other & Adenocarcinoma & 2.09 [1.16-3.79] & 0.01 & $1.98[1.08-3.61]$ & 0.03 \\
\hline KRAS mutation & Positive & Negative & $1.44[0.68-3.05]$ & 0.34 & - & - \\
\hline Prior radiotherapy & Yes & No & $0.62[0.34-1.12]$ & 0.11 & - & - \\
\hline Radiotherapy & $>6$ months & $<6$ months & $14.08[5.36-37.01]$ & $<0.01$ & - & - \\
\hline $\begin{array}{l}\text { Best response to previous } \\
\text { treatment(s) }\end{array}$ & No PD & PD & $0.73[0.35-1.53]$ & 0.4 & - & - \\
\hline $\begin{array}{l}\text { Type of response to } \\
\text { last treatment before } \\
\text { nivolumab }\end{array}$ & No PD & PD & $0.71[0.37-1.35]$ & 0.3 & - & - \\
\hline Weight loss & $>10 \%$ & $\leq 10 \%$ & 0.58 [0.22-1.49] & 0.26 & - & - \\
\hline Lymphocyte count & $<1 \mathrm{G} / 1$ & $\geq 1 \mathrm{G} / 1$ & $0.16[0.04-0.72]$ & 0.02 & - & - \\
\hline Neutrophil count & $>7 \mathrm{G} / 1$ & $<7 \mathrm{G} / 1$ & $0.98[0.4-2.37]$ & 0.96 & - & - \\
\hline Eosinophil count & $\geq 0.5 \mathrm{G} / 1$ & $<0.5 \mathrm{G} / 1$ & $2.1[0.62-7.08]$ & 0.23 & - & - \\
\hline Albuminemia & $<30 \mathrm{~g} / 1$ & $\geq 30 \mathrm{~g} / 1$ & $0.99[0.29-3.41]$ & 0.99 & - & - \\
\hline IRAEs & Yes & No & $2.57[1.30-5.05]$ & $<0.01$ & $2.41[1.21-4.80]$ & 0.01 \\
\hline
\end{tabular}

PD: Progressive disease

IRAEs: Immune relative adverse events

seems to be confirmed for patients with SCC with a benefit in terms of response and PFS but not OS. Lc $\geq 1 \mathrm{G} / \mathrm{l}$ at nivolumab initiation appears to be a biomarker of response but also a prognostic factor for PFS and OS. The other main prognostic markers were weight loss $>$ $10 \%$ and albumin level $<30 \mathrm{~g} / \mathrm{l}$. Occurence of IRAEs seems to emerge as a predictive factor of response, with a longer duration of response and an improvement of PFS and OS. In the literature, PD-L1 expression is not by itself a predictor of checkpoint inhibitors outcome [13]; several additional determinants seem to emerge: an immune-active tumor microenvironment [14], mutational landscape and mutational load $[15,16]$, mismatch repair deficiency [17]. In accordance with our results, the host immune sytem has a key role with absolute number of PNN and Lc [18] as well as low baseline LDH. Contrary to what is described, high absolute Ec was not correlated with response improvement [1921]. Recently, studies have suggested that the response to first line chemotherapy could impact on nivolumab benefit as in this study $[22,23]$. At last, we confirm a correlation between IRAEs and efficacy of nivolumab as already described [24]. Several real-life publications report similar results to ours [25-31] but these retrospective series are often based on efficacy outcomes in selected patients and/or having benefited from nivolumab during a compassionate program. In most cases, data are reported from smaller cohorts limiting the comparison.

A major weakness of our study is the limited control over the data collection who was gathered retrospectively generating missing data, including the PS at nivolumab initiation and several biological criteria. Most patients performed pre-nivolumab blood test externally, which was not systematically reported in the files. There was no centralized database because of the multicentric aspect of this study. But it is the reality of care of these patients in daily practice. Nevertheless, we provided original estimations of efficacy and survival outcomes for patients receiving nivolumab as second-line treatment in real-life. Effectiveness studies can contribute to our knowledge about the use and efficacy of medications [32].

\section{Conclusion}

With an ORR of $22.4 \%$, as described in phase III trials, an 11-month OS, and a satisfactory safety profile, nivolumab offers hope for identical results in a real-life situation. Some predictive factors of response seem to emerge such as squamous histology and occurrence of IRAEs. These results in clinical practice highlight the need for further investigations in larger prospective cohorts.

\section{Declarations}

Acknowledgments: This work was financially supported by the Association Bretonne de Cancérologie Thoracique (ABCT) and we thank all the investigators. We acknowledge all patients for the contribution to this study.

Conflicts of interest and source of funding: None conflicts of interest declared. M. Geier has received funding from the ABCT association (Association Bretonne de Cancérologie Thoracique). For the remaining authors none were declared.

Ethical issues: This non-interventional study was approved by a regional ethics committee and France's national data protection authority (CNIL), according to French law.

Impact statement: Our study confirms the efficacy of nivolumab as second-line treatment in advanced non-small cell lung cancer in a reallife setting with a satisfactory safety profile. Some predictive factors of response seem to emerge such as squamous histology and occurrence of immune-related adverse events. These results in clinical practice highlight the need for further investigations in larger prospective cohorts.

\section{References}

1. Malhotra J, Jabbour SK, Aisner J (2017) Current state of immunotherapy for non-small cell lung cancer. Transl Lung Cancer Res 6: 196-211. [Crossref]

2. Kazandjian D, Suzman DL, Blumenthal G, Mushti S, He K, et al. (2016) FDA Approval Summary: Nivolumab for the Treatment of Metastatic Non-Small Cell Lung Cancer with Progression On or After Platinum-Based Chemotherapy. Oncologist 21: 634-642. [Crossref]

3. Brahmer J, Reckamp KL, Baas P, Crinò L, Eberhardt WE, et al. (2015) Nivolumab versus Docetaxel in Advanced Squamous-Cell Non-Small-Cell Lung Cancer. $N$ Engl $J$ Med 373: 123-135. [Crossref] 
4. Borghaei H, Paz-Ares L, Horn L, Spigel DR, Steins M, et al. (2015) Nivolumab versus Docetaxel in Advanced Nonsquamous Non-Small-Cell Lung Cancer. $N$ Engl J Med 373: 1627-1639. [Crossref]

5. Herbst RS, Baas P, Kim DW, Felip E, Pérez-Gracia JL, et al. (2016) Pembrolizumab versus docetaxel for previously treated, PD-L1-positive, advanced non-small-cell lung cancer (KEYNOTE-010): a randomised controlled trial. The Lancet 387: 1540-1550.

6. Rittmeyer A, Barlesi F, Waterkamp D, Park K, Ciardiello F, et al. (2017) Atezolizumab versus docetaxel in patients with previously treated non-small-cell lung cancer (OAK) a phase 3, open-label, multicentre randomised controlled trial. Lancet 389: 255-265. [Crossref]

7. Eisenhauer EA, Therasse P, Bogaerts J, Schwartz LH, Sargent D, et al. (1990) New response evaluation criteria in solid tumours: revised RECIST guideline (version 1.1). Eur J Cancer Oxf Engl 45: 228-247. [Crossref]

8. Common Terminology Criteria for Adverse Events (CTCAE)CTCAE_4.03_2010-06-14_QuickReference_5x7.pdf.

9. Unger JM, Barlow WE, Martin DP, Ramsey SD, Leblanc M, et al. (2014) Comparison of Survival Outcomes Among Cancer Patients Treated in and Out of Clinical Trials. $J$ Natl Cancer Inst 106: dju002. [Crossref]

10. Shukuya T, Carbone DP (2016) Predictive Markers for the Efficacy of Anti-PD-1/PD L1 Antibodies in Lung Cancer. J Thorac Oncol 11: 976-988. [Crossref]

11. Oya Y, Yoshida T, Kuroda H, Mikubo M, Kondo C, et al. (2017) Predictive clinica parameters for the response of nivolumab in pretreated advanced non-small-cell lung cancer. Oncotarget 8: 103117-103128. [Crossref]

12. Maleki Vareki S, Garrigós C, Duran I (2017) Biomarkers of response to PD-1/PD-L1 inhibition. Crit Rev Oncol Hematol 116: 116-124. [Crossref]

13. Taube JM, Klein A, Brahmer JR, Xu H, Pan X, et al. (2014) Association of PD-1, PD-1 ligands, and other features of the tumor immune microenvironment with response to anti-PD-1 therapy. Clin Cancer Res 20: 5064-5074. [Crossref]

14. Ji RR, Chasalow SD, Wang L, Hamid O, Schmidt H, et al. (2012) An immune-active tumor microenvironment favors clinical response to ipilimumab. Cancer Immunol Immunother 61: 1019-1031. [Crossref]

15. Matsushita H, Vesely MD, Koboldt DC, Rickert CG, Uppaluri R, et al. (2012) Cancer exome analysis reveals a T-cell-dependent mechanism of cancer immunoediting. Nature 482: 400-404. [Crossref]

16. Rizvi NA, Hellmann MD, Snyder A, Kvistborg P, Makarov V, et al. (2015) Mutational landscape determines sensitivity to PD-1 blockade in non-small cell lung cancer. Science 348: 124-128. [Crossref]

17. Lee V, Murphy A, Le DT, Diaz LA Jr (2016) Mismatch Repair Deficiency and Response to Immune Checkpoint Blockade. Oncologist 21: 1200-1211. [Crossref]

18. Mezquita L, Auclin E, Ferrara R, Audigier-Valette C, Tessonnier L, et al. (2017) Baseline-derived neutrophil-to-lymphocyte ratio (dNLR) and lactate dehydrogenase (LDH) to predict the benefit of immune checkpoint inhibitors (ICI) in advanced nonsmall cell lung cancer (NSCLC) patients. J Clin Oncol 35: 9089-9089.
19. Martens A, Wistuba-Hamprecht K, Geukes Foppen M, Yuan J, Postow MA, et al (2016) Baseline Peripheral Blood Biomarkers Associated with Clinical Outcome of Advanced Melanoma Patients Treated with Ipilimumab. Clin Cancer Res Off J Am Assoc Cancer Res 22: 2908-2918. [Crossref]

20. Tanizaki J, Haratani K, Hayashi H, Chiba Y, Nakamura Y, et al. (2018) Peripheral Blood Biomarkers Associated with Clinical Outcome in Non-Small Cell Lung Cancer Patients Treated with Nivolumab. J Thorac Oncol 13: 97-105. [Crossref]

21. Garde-Noguera J, Martorell PM, De Julián M, Altozano JP, Coloma CS, et al. (2018) Predictive and prognostic clinical and pathological factors of nivolumab efficacy in non-small-cell lung cancer patients. Clin Transl Oncol 20: 1072-1079. [Crossref]

22. Kobayashi H, Omori S, Nakashima K, Wakuda K, Ono A, et al. (2017) Response to the treatment immediately before nivolumab monotherapy may predict clinical response to nivolumab in patients with non-small cell lung cancer. Int J Clin Oncol 22: 690-697. [Crossref]

23. Kaderbhai CG, Richard C, Fumet JD, Aarnink A, Ortiz-Cuaran S, et al. (2017) Response to first line chemotherapy regimen is associated with efficacy of nivolumab in non-small-cell lung cancer. Oncoimmunology 6: e1339856. [Crossref]

24. Sato K, Akamatsu H, Murakami E, Sasaki S, Kanai K, et al. (2018) Correlation between immune-related adverse events and efficacy in non-small cell lung cancer treated with nivolumab. Lung Cancer 115: 71-74. [Crossref]

25. Dudnik E, Moskovitz M, Daher S, Shamai S, Hanovich E, et al. (2017) Effectiveness and safety of nivolumab in advanced non-small cell lung cancer: The real-life data Lung Cancer. [Crossref]

26. Schouten RD, Muller M, de Gooijer CJ, Baas P, van den Heuvel M (2017) Real life experience with nivolumab for the treatment of non-small cell lung carcinoma: Data from the expanded access program and routine clinical care in a tertiary cancer centreThe Netherlands Cancer Institute. Lung Cancer. [Crossref]

27. Grossi F, Crinò L, Delmonte A, Turci D, Signorelli D, et al. (2017) MA 10.06 RealWorld Results in Non-Squamous Non-Small Cell Lung Cancer Patients: Italian Nivolumab Expanded Access Program. J Thorac Oncol 12: S1841.

28. Fujimoto D, Yoshioka H, Kataoka Y, Kim Y, Tomii K, et al. (2017) P2.07-024 RealWorld Data of Nivolumab for Previously Treated Non-Small Cell Lung Cancer Patients in Japan: A Multicenter Retrospective Cohort Study. J Thorac Oncol 12: S2424-5.

29. Juergens R, Chu Q, Rothenstein J, De Angelis F, Banerji S, et al. (2017) P2.07-029 CheckMate 169: Safety/Efficacy of Nivolumab in Canadian Pretreated Advanced NSCLC (including Elderly and PS 2) Patients. J Thorac Oncol 12: S2426-S2427.

30. Campelo RG, Areses MC, Baron F, Afonso-Afonso F, Costa M, et al. (2016) P3.02c-98 An Observational Study of the Efficacy and Safety of Nivolumab in Patients with Advanced NSCLC. A Galician Lung Cancer Group. J Thorac Oncol 12: S1339-S1340.

31. Molinier O, Audigier-Valette C, Cadranel J, Monnet I, Hureaux J, et al. (2017) OA 17.05 IFCT-1502 CLINIVO: Real-Life Experience with Nivolumab in 600 Patients (Pts) with Advanced Non-Small Cell Lung Cancer (NSCLC). J Thorac Oncol 12: S1793.

32. Möller HJ (2011) Effectiveness studies: advantages and disadvantages. Dialogues Clin Neurosci 13: 199-207. [Crossref]

Copyright: (C2018 Geier M. This is an open-access article distributed under the terms of the Creative Commons Attribution License, which permits unrestricted use, distribution, and reproduction in any medium, provided the original author and source are credited. 